\title{
Lack of CXC Chemokine Receptor 3 Signaling Leads to Hypertrophic and Hypercellular Scarring
}

\author{
Cecelia C. Yates, ${ }^{* \dagger}$ Priya Krishna, ${ }^{*}$ \\ Diana Whaley, ${ }^{\dagger}$ Richard Bodnar, ${ }^{*}{ }^{\dagger}$ \\ Timothy Turner, ${ }^{\ddagger}$ and Alan Wells ${ }^{\star \dagger \ddagger}$ \\ From the Department of Pathology,* University of Pittsburgh, \\ Pittsburgh Pennsylvania; the Pittsburgh Veteran Affairs Medical \\ Center ${ }^{\dagger}$ Pittsburgh, Pennsylvania; and the Tuskegee University \\ Center for Cancer Research, ${ }^{\ddagger}$ Tuskegee, Alabama
}

CXC chemokine receptor 3 (CXCR3) signaling promotes keratinocyte migration while terminating fibroblast and endothelial cell immigration into wounds; this signaling also directs epidermal and matrix maturation. Herein, we investigated the longterm effects of failure to activate the "stop-healing" CXCR3 axis. Full-thickness excisional wounds were created on CXCR3 knockout ${ }^{(-/-)}$or wild-type mice and examined at up to 180 days after wounding. Grossly, the $\mathrm{CXCR}^{-/-}$mice presented a thick keratinized scar compared with the wild-type mice in which the scar was scarcely noticeable; histological examination revealed thickening of both the epidermis and dermis. The dermis was disorganized with thick and long collagen fibrils and contained excessive collagen content in comparison with the wild-type mice. Interestingly, the $\mathrm{CXCR}^{-/-}$ wounds presented lower tensile/burst strength, which correlates with decreased alignment of collagen fibers, similar to published findings of human scars. Persistent Extracellular matrix turnover and immaturity was shown by the elevated expression of proteins of the immature matrix as well as expression of matrix metallopeptidase-9 MMP-9. Interestingly, the scars in the $\mathrm{CXCR}^{-1-}$ mice presented evidence of de novo development of a sterile inflammatory response only months after wounding; earlier periods showed resolution of the initial inflammatory stage. These in vivo studies establish that the absence of $\mathrm{CXCR}^{-/-}$ signaling network results in hypertrophic and hypercellular scarring characterized by on-going wound regeneration, cellular proliferation, and scars in which immature matrix components are undergoing increased turnover resulting in a chronic inflammatory process. (Am J Pathol 2010, 176:1743-1755; DOI: 10.2353/ajpath.2010.090564)
Scar formation after excisional wound repair results from a dysfunction in remodeling the two skin compartments, the ectodermally-derived epithelial epidermis and the mesodermally-derived mesenchymal dermis. ${ }^{1}$ As a result, there is excessive deposition and misalignment of extracellular matrix proteins. Hypertrophic scar formation, resulting in a thickened skin, which is raised above the unwound tissue, is caused by increased wound cellularity and excessive matrix. Although it is well recognized that a scar results from an imbalance in cellular responses to promotive and inhibitory signals ${ }^{2}$ that signal in a paracrine fashion between the dermis and epidermis, ${ }^{3,4}$ the factors that influence this balance between production and degradation are only now being ascertained.

Scarring is a challenge to study because the animal models for scarring are such that the hypertrophy occurs in privileged sites, on physiochemical insult, or in a genetically influenced manner. ${ }^{5,6}$ In addition, these animal models do not recapitulate the complex situation of human hypertrophic scars or keloids. For instance, hypertrophic scars generated by traction forces being applied during the regenerative phase of healing present a mixed picture of both dermal and epidermal hyperproliferation. ${ }^{2}$ Still, this mixed picture aspect of wound hypertrophy is reminiscent of the early stages of human wound hypertrophic scarring. ${ }^{7}$ Thus, the challenge in these models is to understand the signaling network that under normal conditions limits the wound healing response to prevent human hypertrophic scars. We have taken the approach to determine whether signals that arise late in the regenerative phase act not only to drive wound resolute but also prevent the emergence of hypertrophic scarring.

Earlier, we had found that the exuberant cellular responses of wound repair are resolved late in the healing process, at least in part, by a related group of chemo-

Supported by grants from the National Institute of General Medical Science of the National Institutes of Health. Services in kind were provided by the Pittsburgh Veteran Affairs Medical Center and National Cancer Institutes U54 Tuskegee University.

Accepted for publication December 1, 2009.

Address reprint requests to Alan Wells, M.D., D.M.Sc, University of Pittsburgh, Department of Pathology, 3550 Terrace St, Scaife Hall, S-713, Pittsburgh, PA 15261. E-mail: wellsa@upmc.edu. 
kines that appear in the late remodeling and persist into the resolving phase of wound healing; this is the time at which cellularity is reversed and the wound bed matures. ${ }^{8,9}$ These chemokines, IP-9/CXCL11 expressed by re-differentiating keratinocytes and IP-10/CXCL10 produced by maturing endothelium deep in the dermis, ${ }^{4,10,11}$ both bind to the ubiquitous seven transmembrane G-protein couple chemokine receptor, CXCR3. ${ }^{12}$ Signaling through CXCR3 blocks the growth factor induced motility of fibroblasts and endothelial cells by suppressing m-calpain, CAPN2, activation. ${ }^{13,14}$ Yet in contrast, these chemokines increase keratinocytes migration via lessened adhesiveness secondary to u-calpain, CAPN1, activation..$^{15}$ It is the cellular effects and, most important, the timing of the expression of IP-9 and IP-10 that suggests these chemokines are at least part of the key communication between the dermis and epidermis that signals an end to the remodeling phase and initiation of the resolving phase of wound repair.

These CXCR3 ligands signal between the two compartments to stop wound healing. Using mice lacking either the receptor or the CXCL11/IP-9 ligand as in vivo models, we found that in the absence of this signaling axis, excisional wounds matured at a retarded rate with a still weakened and immature dermis even 90 days after wounding. ${ }^{9}$ Furthermore, while there was a delay in reepithelialization, as predicted by the promotive effects on keratinocytes, the closed wounds presented an epidermis that contained more cell layers than the syngenic wild-type mice. However, in both models the skin had developed normally despite the absence of the receptor or ligand, and the wounds did close and were maturing, reflecting a critical redundancy in wound repair elements. ${ }^{1}$ Thus, we expected that at extended time periods the wounds would fully resolve. Surprisingly, we now report that not only does the wound resolution not go to completion, but these wounds appear to revert to an ongoing regenerative-like process that results in a visible scar characterized by hyperkeratinization, excessive but dysfunctional collagen matrix, and an inflammatory infiltrate.

\section{Materials and Methods}

\section{Mouse Model System}

The CXCR3-devoid mice were the kind gift of Bao Lui and William Hancock, and the mice were generated as previously described. ${ }^{16} \mathrm{CXCR}^{-1-}$ female mice were bred with $\mathrm{CXCR}^{-1-}$ male mice, and all of the offspring were screened by PCR before use for the study. ${ }^{9}$ Control, age-matched C57BI6/J mice were obtained from Jackson Laboratories (Bar Harbor, ME). IP-9/CXCL11 expression by basal keratinocytes was abrogated by expression of an antisense construct driven off the $\mathrm{K} 5$ promoter (a kind gift from Dr Jose Jorcano, National Research Centre for Energy, Environment and Technology, Madrid, Spain). ${ }^{17}$ In brief, the construct was generated by cloning the IP-9 cDNA into the SnaB1 site of the pBK5 vector, which contains $5.2 \mathrm{~kb}$ of the bovine cytokeratin $\mathrm{K} 5$ pro- moter. ${ }^{18}$ The transgenic mice are referred to as IP-9AS. The IP-9AS transgene was expressed in FVB mice, which were used herein for the control mice background. All studies on these animals were performed in compliance with and after approval by the Institutional Animal Care and Use Committees of the Veteran's Administration and University of Pittsburgh. These animals were housed in a facility of the Veteran's Affair Medical Center (Pittsburgh, PA) accredited by the Association for the Assessment and Accreditation of Laboratory Animal Care. Serological analyses did not detect blood borne pathogens or evidence of infection. Mice were housed in individual cages after wounding and maintained under a 12-hour light/ dark cycle and temperature in accordance with the guidelines approved by the Institutional Animal Care and Use Committee.

\section{Wounding}

Male and female mice ( 7 to 8 weeks of age and weighing approximately $25 \mathrm{~g}$ ) were anesthetized with an intraperitoneal injection containing ketamine $(75 \mathrm{mg} / \mathrm{kg})$ and $x y$ lazine (5 mg/kg). The backs were cleaned, shaved, and sterilized with betadine solution. For full-thickness wounds, a circular 2-cm full-thickness wound through the epidermis and dermis was made on one side of the dorsal midline (to minimize wound contraction) by using sharp scissors, and the contralateral uninjured skin served as a control. The wounds were covered with liquid occlusive dressing (New-Skin; Medtech, Jackson, WY). India ink was used to mark the wound site at the time of wounding; after healing, the wound site was marked externally on the skin by marker every 2 weeks.

\section{Histological Analyses}

\section{Mouse}

Wound bed biopsies surrounded by a margin of unwounded skin were collected at days $60,90,120$, and 180 after wounding. Wound biopsies were fixed in 10\% buffered formalin, processed, and embedded in paraffin blocks by using standard protocols. Tissue sections (4 $\mu \mathrm{m})$ were stained with $\mathrm{H} \& \mathrm{E}$ and analyzed for general tissue and cellular morphology. Collagen deposits were evaluated by Masson's Trichrome staining (for content) and Picrosirius Red staining (for alignment and organization). ${ }^{9}$ Wound biopsies were compared with that of the contralateral unwounded skin by using Meta-Morph analysis software (Molecular Devices, Sunnyvale, CA). For Picrosirius Red birefringence under polarized light, distribution of fibrils in terms of thickness (cross-sectional area) and arrangement in terms of length of the collagen scars were quantitatively analyzed by using Meta-Morph. Polarization microscopy reveals tightly packed thick and long fibrils of type 1 collagen as either bright red-orange intense birefringence in tissue and thin short loose fibrils as yellow-green. Percent staining of mature fibers was determined by comparing the total staining intensity of the birefringence (area of staining summed for intensity of 
pixel) of wound biopsies compared with the biopsies of the contralateral unwounded skin.

\section{Human}

Human skin samples, obtained via an honest broker from a de-identified tissue bank, were used for the histological study of hypertrophic scars. Skin was obtained from the shoulder (TB08-83), malar (TB08-84), and chest (TB08-85) regions. Standard 5- $\mu \mathrm{m}$ sections were cut and embedded in paraffin were used. The use of the specimens herein was deemed exempt category $4 \mathrm{e}$ by the University of Pittsburgh Institutional Review Board because this tissue was received as excess pathological tissue devoid of protected health information.

\section{Epidermal and Dermal Maturation}

Histopathological examination of mouse tissue was performed blinded by a trained histopathologist. Qualitative assessments were made concerning aspects of dermal and epidermal maturation as previously described. ${ }^{18}$ In brief, the samples were scored on a scale of 0 to 4 for epidermal healing (0, no migration; 1 , partial migration; 2 , complete migration with partial keratinization; 3 , complete keratinization; and 4, normal epidermis) and dermal healing ( 0 , no healing; 1 , inflammatory infiltrate; 2 , granulation tissue present-fibroplasias and angiogenesis; 3 , collagen deposition replacing granulation tissue $>50 \%$; and 4 , complete healing).

\section{Wound Measurements}

Epidermal, dermal, and wound thickness and wound length measurements were based on those made from H\&E-stained tissue sections at $10 \times$ magnification. We measured five separate sections for the epidermal (thickness of epidermis in scar), dermal (thickness of dermis in scar), and wound thickness (entire cross section of the scar). Wound length was measured from uninjured skin on one side of the scar across the dermis to the other side. Five fields of unwounded skin from both sides of the scar were measured for controls.

\section{Inflammation}

Acute inflammation was defined as the presence of neutrophils, and chronic inflammation by the presence of plasma and monocytic cells ( 0 , none; 1 , slight; 2 , moderate; and 3 , abundant). In both situations the scale was the relative level of cells per high-power field as previously described. ${ }^{18}$

\section{Tissue Gram Stain}

Sections were Gram-stained by standard protocols and were analyzed under oil immersion $60 \times$ magnification for histological I assessment. For the Gram reaction (Grampositive or Gram-negative), morphology (eg, coccus, rod, or formation of chains or clusters) and number of organisms seen per field were determined.

Antigen retrieval was performed first by use of Clear Rite3 (Thermo Scientific, Pittsburgh, PA) in three 10minute washes, followed by deparaffinization with 100\% and $95 \%$ ethanol for 3 minutes, and $75 \%$ alcohol for 1 minute. Slides were rinsed in distilled $\mathrm{H}_{2} \mathrm{O}$ and then incubated in proteinase $\mathrm{K}$ for 30 minutes. A washing buffer using 20X PBS ( $\mathrm{pH} 7.2$ ) was used three times for 1 minute for each wash. A peroxidase blocking solution $(0.3 \%$ $\mathrm{H}_{2} \mathrm{O}_{2}$ in methanol) was then applied for 10 minutes at room temperature followed by a washing step. Slides were then incubated for 30 minutes with a serum-blocking agent by using antibody of the same species as the secondary antibody. Primary antibodies used were fibronectin (Affinity Bioreagents, Golden, CO), tenascin C and decorin (R \& D Systems, Inc, Minneapolis, MN), von Willebrand factor, matrix metallopeptidase-9 (MMP-9), transforming growth factor- $\beta$ receptor, Ki-67, collagen I and III, Macrophage, and $\alpha$-smooth muscle actin (all from Abcam, Cambridge, MA), and slides were incubated in primary antibody for 1 hour at 1:50 dilution. Biotinylated secondary antibody incubation for 30 minutes at room temperature was followed by detection, which was accomplished by using an avidin-biotin complex peroxidase solution (Vectastain, Burlingame, CA) for 30 minutes at room temperature. Peroxidase/chromagen substrate agent was applied for at least 5 minutes and until desired stain intensity was achieved. A washing step with PBS Tween 20 was performed after each antibody incubation, except for between the serum block and primary antibody (three washes for 2 minutes each). Slides were left in Clear-Rite3 twice for 5 minutes each time and then were cover-slipped with mounting medium. Slides were then viewed and analyzed under an Olympus BX40 light microscope by using Spot Advanced software (Diagnostic Instruments, Inc, Sterling Heights, MI).

Standard terminal deoxynucleotidyl transferase-mediated dUTP nick-end labeling (TUNEL) assay (Roche Diagnostics Corporation, Indianapolis, IN) was performed as described earlier ${ }^{9}$ and pseudo-colored red to better distinguish apoptotic nuclei (red from total nuclei DAPI, 4',6-diamidino-2-phenylindole). Quantification of dermal apoptotic nuclei was performed by using Meta-Morph software (Molecular Devices).

\section{Hydroxyproline Assay}

A hydroxyproline assay was performed as a marker of collagen synthesis in wound tissues. Wet skin tissue was weighed and dried at $110^{\circ} \mathrm{C}$ for 24 hours in glass vacuoles. This was then hydrolyzed with $6 \mathrm{~N} \mathrm{HCL}$, and oxygen was removed and replaced with nitrogen for incubation under anoxic conditions for 24 hours at $110^{\circ} \mathrm{C}$. $4-\mathrm{Hy}$ droxy-l-proline standards ( 0 to $5 \mu \mathrm{g} / \mathrm{ml}$ ) were created from a $10 \mu \mathrm{g} / \mathrm{ml}$ hydroxyproline stock solution. Samples were incubated with $0.5 \mathrm{ml}$ of chloramine-T solution (50 $\mathrm{mmol} / \mathrm{L}$ chloramine-T, $30 \% \mathrm{v} / \mathrm{v}$ ethylene glycol monomethyl ether, $50 \% \mathrm{v} / \mathrm{v}$ hydroxyproline buffer $[0.26 \mathrm{M}$ citric acid, $1.46 \mathrm{M}$ sodium acetate, $0.85 \mathrm{M}$ sodium hydroxide, $1.2 \% \mathrm{v} / \mathrm{v}$ glacial acetic acid], distilled $\mathrm{H}_{2} \mathrm{O}$ for the remain- 
ing volume), followed by $0.5 \mathrm{ml}$ of $3.15 \mathrm{M}$ perchloric acid for 5 minutes at room temperature. Hydroxyproline standards and samples were read in a 96-well plate at 557 $\mathrm{nm}$ on a spectrophotometer (SpectraMax plus; Molecular Devices). Values are expressed as micrograms of hydroxyproline per milligram of protein.

\section{Tensile Strength}

Biopsies were bisected, wrapped flat in foil, snap-frozen in liquid nitrogen, and then stored at $-80^{\circ} \mathrm{C}$. For the tensile strength measurements, the frozen specimens were divided into two samples, the cross-sectional area was measured with calipers, and then the samples were clamped in a tensiometer and force-exerted until wound disruption. Measurements were recorded by a customized computer software program, and tensile strength was calculated by using the following formula: maximum tensiometer reading (converted to grams) divided by cross-sectional area $\left(\mathrm{mm}^{2}\right)=$ tensile strength $\left(\mathrm{g} / \mathrm{mm}^{2}\right)$. The results for individual specimens from one wound were combined to determine an average tensile strength per wound. The average tensile strength per wound was tabulated for each group. Tensile strength was normalized to unwounded skin of each phenotype and within each experimental run.

\section{Keratinocyte-Fibroblast Transwell Co-Cultures}

Primary C57BI6/J wild-type or $\mathrm{CXCR} 3^{-1-}$ keratinocytes were seeded on Transwell clear inserts of polyester membrane with a $0.4-\mu \mathrm{m}$ pore size and a diameter of $12 \mathrm{~mm}$ for 12-well plates (Costar Corporation, Corning, NY). ${ }^{4}$ Primary C57BI6/J wild-type or CXCR3 ${ }^{-1-}$ fibroblasts were plated on the lower chambers of 12-well plastic dishes and were grown to confluence. After both the keratinocytes and fibroblasts reached confluence, the cells were quiesced in medium containing $0.1 \%$ dialyzed serum for fibroblasts and growth factor-deficient medium for keratinocytes. The inserts containing the keratinocytes were transferred on to 12-well dishes with the fibroblasts. The keratinocytes were then stimulated with or without $2000 \mathrm{U}$ of human interferon- $\gamma$ (IFN- $\gamma$ ) for 24 hours in the presence or absence of epidermal growth factor (EGF; $10 \mathrm{nmol} / \mathrm{L}$ ) and/or anti-CXCL11 $(3 \mu \mathrm{g} / \mathrm{ml})$. Inserts with keratinocytes but not treated with IFN- $\gamma$ and inserts without keratinocytes but treated with IFN- $\gamma$ and fibroblast stimulation alone with recombinant CXCL11 served as controls. These concentrations were determined empirically to provide either maximum motility or inhibition without toxicity. Cell migration assay of the fibroblasts was performed, and photographs were taken at 0 and 24 hours and the relative distance moved into wounded area at the acellular front was determined.

\section{Statistical Analyses}

All assays were performed on a minimum of five mice or four human specimens. Quantitative assays were performed at least three times each in triplicate experiment, and histological quantitations were performed on at least five microscopic fields of each specimen. Results are expressed as mean \pm SEM per specimen because all individual assay measurements were performed in replicate. Statistical differences between groups were determined by the Kruskal-Wallis test. For difference of a singular group, analysis of variance analyses were performed. Significance was claimed for $P<0.05$.

\section{Results}

\section{Wounds in Mice Lacking CXCR3 Results in a Visible Scar}

We have published that the absence of CXCR3 signaling leads to impaired wound repair; CXCR3 ${ }^{-1-}$ mice wound exhibited hyperkeratinization, thickened epidermis, disorganized and hypercellular dermis, and excessive vascularity even 90 days after wounding. ${ }^{9}$ However, the long-term consequences of this "failure to stop" healing were not predictable because the wounds appeared to be maturing and resolving at out to 90 days when examined histologically. We therefore created full-thickness excisional wounds on the mouse dorsum and followed the wounds for 180 days at which point the abnormality in healing was grossly apparent. The wounds in the $\mathrm{CXCR3}^{-1-}$ mice still appeared unresolved with the presence of a scaly raised area (Figure 1A). Histological assessment confirmed that the abnormal healing patterns seen grossly at day 180 were a result of the excessive epidermal cell layers, hyperkeratinization, excess fibroblasts and collagen, and persistent chronic inflammation, resulting in an overall thicker scar (Figure 1B). Quantification of the wound showed a significant delay in wound maturation of the $\mathrm{CXCR}^{-1-}$ wounds in comparison with that of the wild-type mice wounds (Figure 1C). This was reflected by increased thickness of both the epidermis and dermis of the wounds in the $\mathrm{CXCR}^{-1-}$ mice (Figure 1, D and E). CXCR3 ${ }^{-1-}$ wounds appear to continue to remodel and not fully mature in wound thickness and length over a longer period of time compared the wild-type mice (Figure 1, F and G).

Interestingly, these 6-month-old wounds in the $\mathrm{CXCR}^{-1-}$ mice have similarities with the features of a human hypertrophic scar (though missing some of the architectural changes of the human hypertrophic situation; Figure $1 \mathrm{H}$ ), whereas the wounds in wild-type mice closely resemble unwounded skin as would be expected from a healed wound. Hypertrophic scars are usually hyalinized, thickened, and have multidirectional growth of collagen bundles. ${ }^{19}$ At 180 days the wounds in the $\mathrm{CXCR3}^{-1-}$ mice showed similarly thickened epidermis with hyperkeratinization and dermal hypercellularity, excessive and disorganized collagen bundles. These similarities suggest that the $\mathrm{CXCR}^{-1-}$ mouse wound model could be used as a model for studying hypertrophic and hypercellular scar formation. 

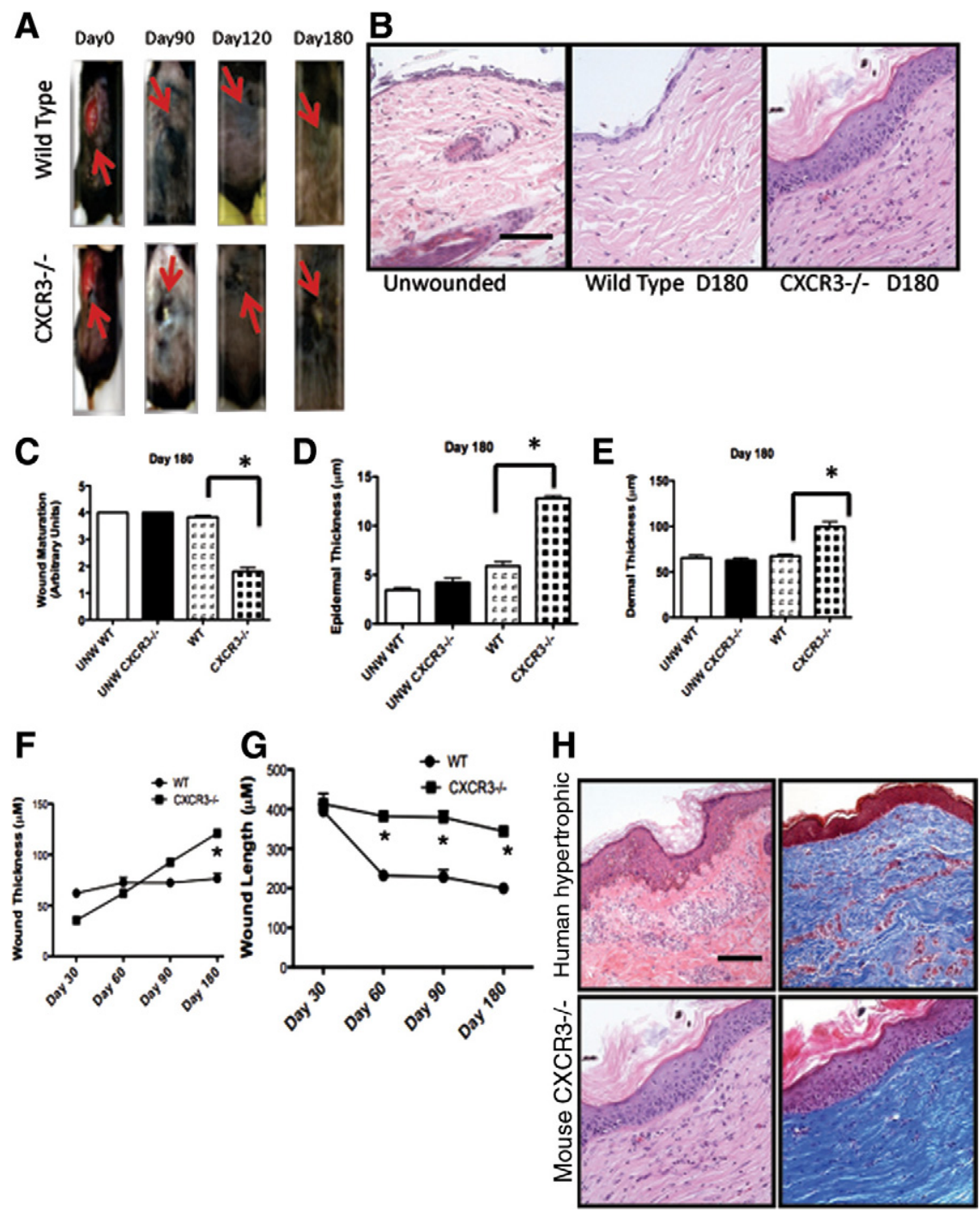

\begin{abstract}
Figure 1. Wounds in $\mathrm{CXCR} 3^{-/-}$mice present hypertrophic characteristics. $\mathrm{CXCR}^{-/-}$fullthickness wounds show altered healing patterns. A: Representative photographs are shown of full-thickness wounds (arrows) at various days up to day 180. At day 180 the wound in $\mathrm{CXCR}^{-/-}$mice presented a visible keratinized scab, whereas wounds in wild-type mice appeared completely healed. B: Histological examination and analysis by H\&E staining of these 6-month-old wounds of CXCR3 ${ }^{-1-}$ mice resemble the features of hypertrophic scarring. C: Measurement of overall wound maturation including epidermal thickness, hyperkeratinization, chronic inflammation, fibroblast cellularity, vascularity, and collagen modeling. Quantification of these wounds revealed that wound maturation in $\mathrm{CXCR}^{-/-}$mice was significantly impaired in comparison with that in the wild-type (WT) mice. D and E: Epidermal and dermal thickness measurements showed $\mathrm{CXCR}^{-1}$ wounds to be significantly thicker than those of wild-type and unwounded wounds. F and $\mathbf{G}$ : Wound thickness and length are greater in $\mathrm{CXCR}^{-1-}$ over a longer period of time compared the wild-type mice. Original magnification, $\times 10$. H: The wounds at 180 days resemble those of human hypertrophic scars in both H\&E (left) and Masson's Trichrome (right) staining. Representative micrographs and mean \pm SEM for the quantification ( $n=6$ for each mouse genotype per time point); ${ }^{*} P<0.05$.
\end{abstract}

\section{Fibroplasia and Excessive but Misaligned Collagen Characterize the Dermis in the Absence of CXCR3}

The main role of the remodeling phase fibroplasia is to rapidly replace the dermal matrix. This occurs in three steps with initial generation of an immature provisional matrix followed by replacement of the provisional matrix with a collagen I-rich matrix that is then aligned, these latter two stages secondary to fibroblast "differentiation"20; the fibroplasia is then reverted by apoptosis. It is these two latter phases and the involution of the fibroplasia that appear compromised in the wounds in CXCR3devoid mice (Figure 2). ${ }^{21}$ Masson's Trichrome staining that detects collagen production shows $\mathrm{CXCR}^{-1-}$ mice with greater collagen content in comparison with wildtype shown by the intensity of the staining (Figure 2A). Although quantification of the trichrome staining suggest $50 \%$ greater amounts of collagen in wounds in the absence of CXCR3 (Figure 2B), interestingly, in the wildtype mice, the healed wounds had similar levels of collagen to unwounded skin. Picrosirius Red staining, which detects appropriately stressed and aligned collagen bundles, showed at 180 days the collagen in to be short, actively growing and remodeling, immature fibers that fail to provide strength in the absence of CXCR3 (Figure 2, C and D). Tensiometry was performed on these wounds to determine the tensile strength, which is the end goal of the dermal matrix regeneration. The wounds in the $\mathrm{CXCR}^{-1-}$ mice required significantly less force to break compared with the healed wounds in the wildtype mice; these latter wounds demonstrated the expected $20 \%$ or reduction in strength compared with unwounded skin, which is noted to follow dermal wound repair validating the measurements (Figure $2 \mathrm{E}$ ) ${ }^{20}$ These results suggest that the lack of collagen alignment and maturation results in less strength in the absence of CXCR3 signaling.

Apoptosis of dermal cells is critical during the resolving phase for dermal maturation in which the few remaining fibroblasts are synthetic and contractile rather than proliferative/apoptotic. ${ }^{21,22}$ Interestingly, hypertrophic scars exhibit a significantly higher level of apoptosis than normal healed wounds, ${ }^{23}$ suggesting that the resident 
A

Unwounded Wild Type CXCR3-/-

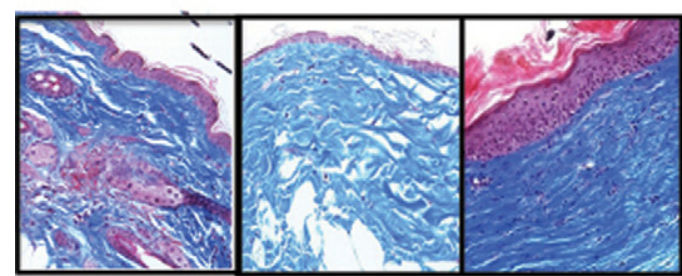

C
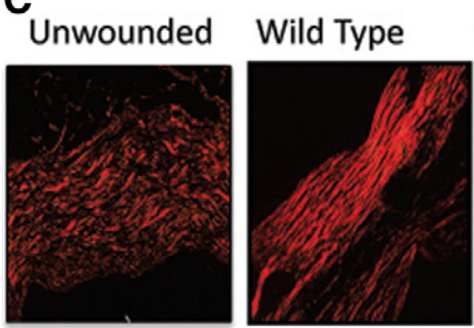

CXCR3-/-

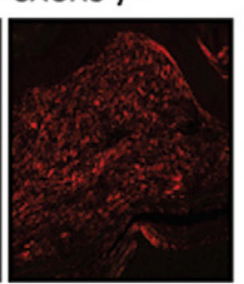

B

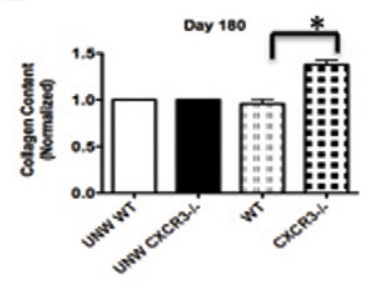

D

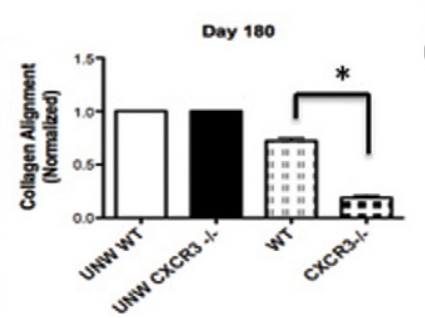

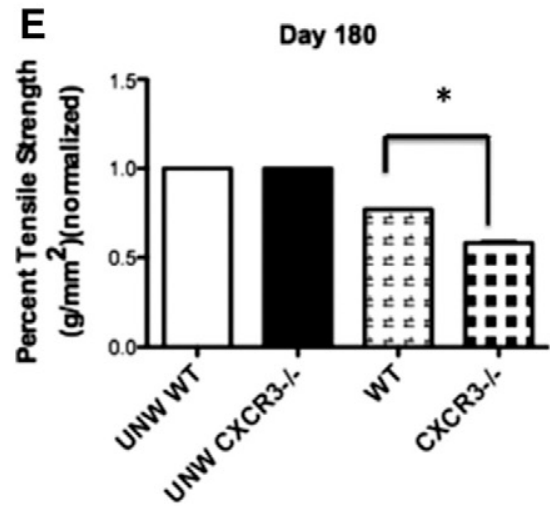

Figure 2. Wounds in CXCR3 $3^{-/-}$mice present excessive collagen remodeling. A: Masson's Trichrome images of a wound in CXCR3 ${ }^{-/-}$and wild-type mice presented distinguishable patterns of collagen remodeling. B: New collagen deposition was quantitatively measured by using Masson's Trichrome microscopic images and MetaMorph analysis of the images of full-thickness wounds, confirming that wounds in the CXCR $3^{-1-}$ mice resulted in significantly more collagen than those in the wild-type (WT) mice at day 180. C: Picrosirius Red staining highlighted that the collagen in wounds in mice devoid of CXCR3 was less organized and shorter, denoting an immature scar. D: Quantitative analysis showed a significant difference between the wild-type and CXCR3 ${ }^{-/-}$mice at day 180 . E: Assessment of the mechanical properties shows wounds in CXCR $3^{-\prime-}$ mice are weaker in comparison with wild-type. Representative micrographs and mean \pm SEM for the quantitation ( $n=6$ for each mouse genotype per time point); ${ }^{*} P<0.05$. Scale bar $=50 \mu \mathrm{m}$.

fibroblasts are in the mitogenic phase representative of "undifferentiated" fibroblasts. Fibroblast apoptosis was evaluated in both the $\mathrm{CXCR}^{-1-}$ and wild-type mice. TUNEL staining demonstrated significantly more apoptotic cells in the wound of $\mathrm{CXCR}^{-1-}$ mice (Figure $3, \mathrm{~A}$ and $\mathrm{B})$, with the majority of these apoptotic cells being dermal fibroblasts as determined by $\alpha$-smooth muscle actin staining (Figure $3 \mathrm{C}$ ). These data correlate with the continuous remodeling of the collagen fibers and hypercellularity seen in the $\mathrm{CXCR}^{-1-}$ mice at this late stage of repair. This increase in cell death is balanced by an increased cell proliferation as determined by positive Ki-67 staining (Figure 3D). Compared with the relative dormant status of the wild-type mice, $\mathrm{CXCR}^{-1-}$ mice wounds show an increase in cell death in the dermis coupled with active proliferation of cells in the dermis and also in the epidermis. These results suggest that the active microenvironment seen in the $\mathrm{CXCR}^{-1-}$ mice wounds is contributing to the hypertrophic scars characteristic of these wounds.

\section{The Scar Matrix Remains Immature in the Absence of CXCR3}

Mature skin is characterized by a relatively quiescent dermal matrix with only a low level of synthesis and proteolysis occurring in the absence of insult. Imbalances in expression of key extracellular matrix proteins result in a number of pathological conditions including fibrosis. Previously, we have seen the persistence of the matrix proteins fibronectin and tenascin $C$ in the $\mathrm{CXCR}^{-1-}$ mice up to 90 days after wounding. ${ }^{9}$ Thus it was not totally unexpected to see the expression of MMP-9, a diverse proteolytic enzyme involved in Extra- cellular matrix turnover and tissue remodeling, being much higher on $\mathrm{CXCR}^{-1-}$ mice wounds than that of the wild-type mice (Figure 4A). Studies show that up-regulation of MMP-9 in the early healing phases and rapid decrease during remodeling phase promotes timely reepithelialization and limits excessive scar formation. MMP-9 expression becomes pronounced on day 2 in both wild-type and $\mathrm{CXCR}^{-1-}$ wounds and then decreases (data not shown); its continued high-level presence at 180 days after wounding in $\mathrm{CXCR}^{-1-}$ mice is a mark of pathological wound repair. As such, we analyzed these wounds for production of collagen I, collagen III, fibronectin, and tenascin C. Tenascin C is an extracellular matrix glycoprotein whose presence is limited in uninjured tissues yet is expressed at high levels during wound healing and in response to invasive wounds. ${ }^{24}$ In normal mature wounds, tenascin is nearly absent (resembling the distribution in normal skin). We observed a strong expression of tenascin $\mathrm{C}$ in the dermal compartment of all of the 180-day scars of the $\mathrm{CXCR}^{-1-}$ mice, yet in the wild-type mice wounds tenascin is almost completely absent (Figure 4A). This suggests that the mechanism for down-regulation of tenascin $\mathrm{C}$ is deficient in the $\mathrm{CXCR3}^{-1-}$ mice. Although little is known about the altered regulation of fibronectin, overexpression of fibronectin also has been noted as an important aspect of hypertrophic wounds although little is known about the altered regulation of this extracellular component. ${ }^{25}$ When comparing the CXCR3-devoid mice to wild-type mice, 180-day scars were observed to have an enhanced fibronectin expression in the $\mathrm{CXCR}^{-1-}$ mice (Figure 4A), providing further molecular evidence of a hypertrophic scar. These data suggest that tissue degradation and remodeling are still occurring in the $\mathrm{CXCR}^{-1-}$ mice at 


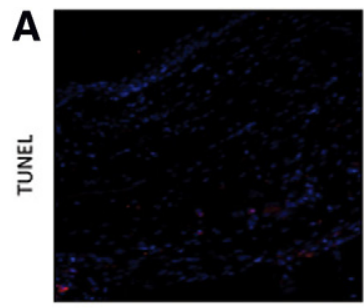

Wild Type D180

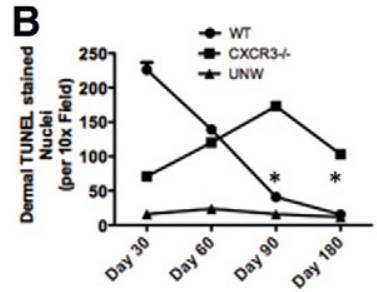

D

Wild Type D180
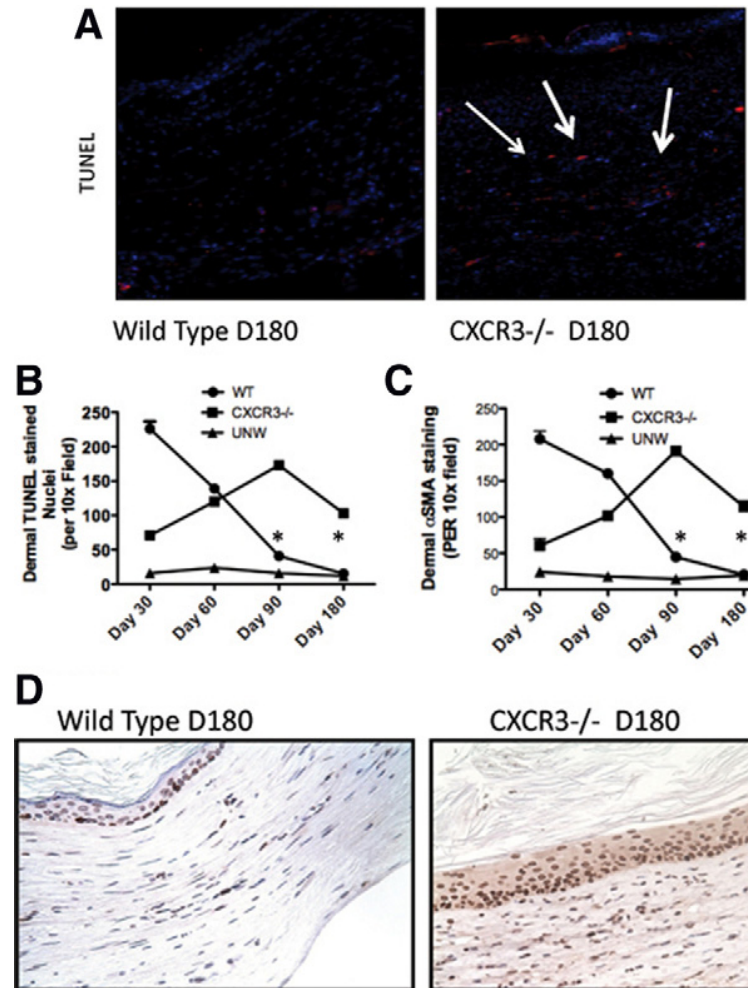

CXCR3-/- D180

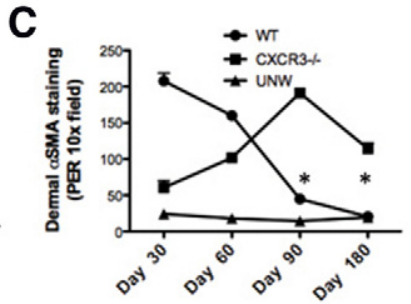

CXCR3-/- D180

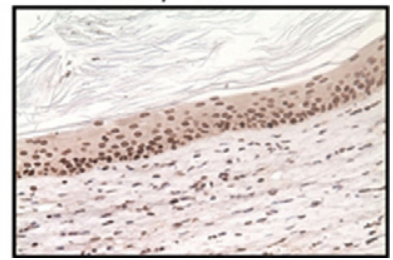

Figure 3. Wounds in $\mathrm{CXCR} 3^{-/-}$mice demonstrate continued turnover of the dermal and epidermal cells. Apoptosis was assessed in the wound bed in $\mathrm{CXCR}^{-1-}$ mice by in situ TUNEL staining throughout the healing process. A: Representative micrographs $(n=3$ for each mouse genotype per time point) show apoptotic signaling determined by DNA fragmentation associated with apoptosis. Detection of apoptotic cells (red) showed fewer apoptotic events in wounds of wild-type (WT) mice than in $\mathrm{CXCR}^{-1-}$ mice at 180 days after wounding; nuclei are stained by DAPI stain (blue). (Arrows indicate TUNEL stained cells). B: Quantitative analysis of dermal TUNEI stained nuclei. C: Quantitative confirmation of dermal fibroblasts was shown by $\alpha$-smooth muscle actin stained positive cells. D: Histological sections taken at day 180 after wounding were stained with Ki-67 to demarcate cells in proliferative phase. The wounds in CXCR $3^{-1-}$ mice exhibit epidermal hypercellularity with a thicker epithelial layer compared with the wild-type mice wounds. In the wounds of the $\mathrm{CXCR}^{-1-}$ mice, there is evidence of proliferation well above the basal layers. Representative micrographs ( $n=6$ for each mouse genotype per time point). Scale bar $=50 \mu \mathrm{m} .{ }^{*} P<0.05$.

this late time point, resembling the pathology seen in human hypertrophic scars.

Synthesis and degradation of collagen is an essential component of wound healing, and excessive accumulation of collagen results in hypertrophic scars and keloids. ${ }^{26}$ Collagen production was examined in the scars. An increase in collagen I, collagen III, and the proteoglycan decorin was observed in these scars in comparison with that of the wild-type animals (Figure 4A). The increase in collagen by staining was confirmed by an increase in hydroxyproline levels compared with wild-type mice (Figure 4B). Because the previous data have shown that established hypertrophic and keloid scars fibroblasts synthesize normal amounts of collagen per cell, ${ }^{19,27}$ we attribute the increase level of collagen production seen the $\mathrm{CXCR}^{-1-}$ scars to increased numbers of synthetic fibroblasts. The composition of the matrix does not point clearly toward a hypertrophic scar because the increase in decorin noted in these mice is more in line with keloid development; however, in the initial year of aberrant hu-

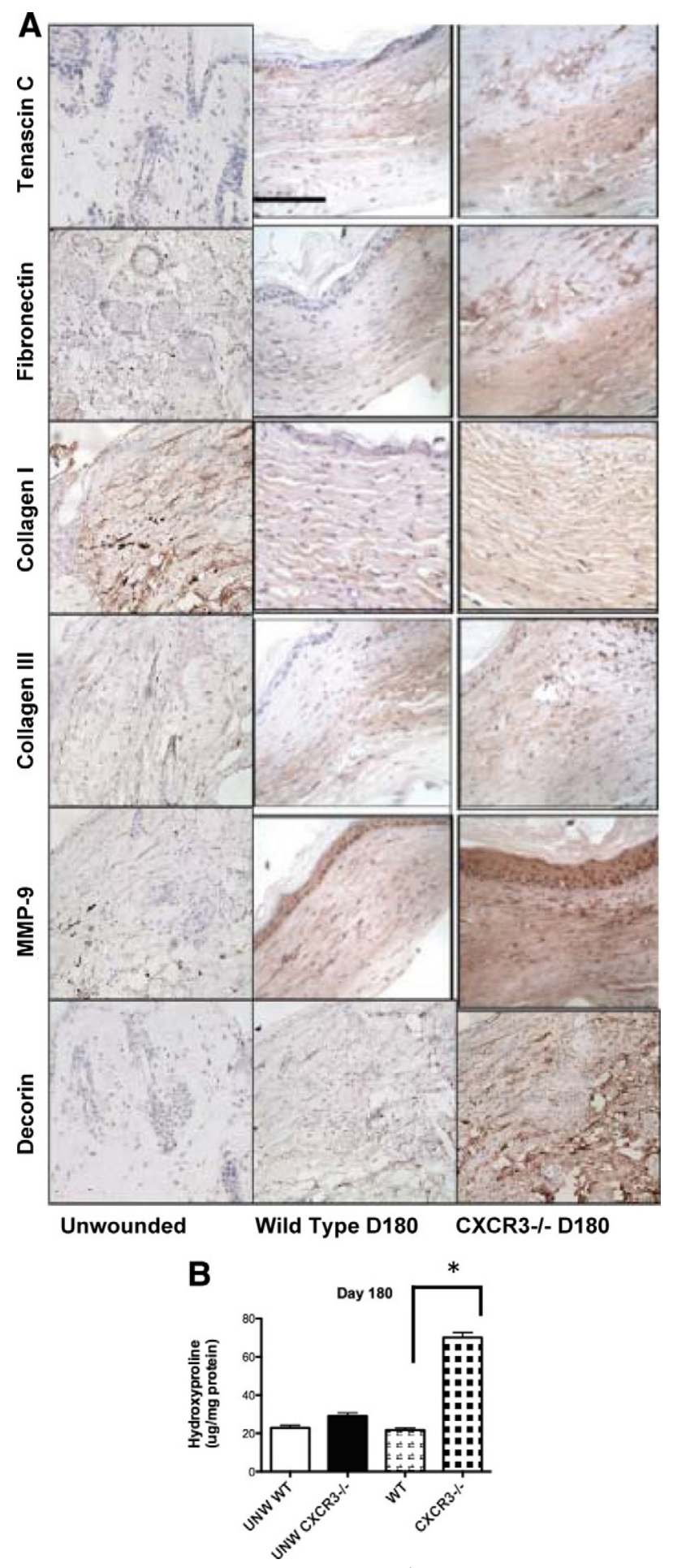

Figure 4. A: Wound immaturity in $\mathrm{CXCR} 3^{-/-}$mice is reflected in persistence of select extracellular matrix proteins. As the scar develops and matures, MMP-9 expression decreases in the wounds in wild-type mice, yet in the $\mathrm{CXCR}^{-/-}$mice strong expression is still present in high levels as late as day 180 after wounding. Staining of provisional matrix proteins tenascin C and fibronectin shows continued enhanced expression in wounds of $\mathrm{CXCR}^{-1-}$ mice in contrast to the wild-type mice that at 180 days after wounding closely resemble the negligible expression seen in normal skin. Collagen I and Collagen III levels in wounds of CXCR3 ${ }^{-/-}$resemble those seen in hypertrophic scarring, as did the elevated levels of decorin. B: Hydroxyproline levels in wounds in $\mathrm{CXCR} 3^{-/-}$mice are significantly increased compared with those in wild-type (WT) mice. Representative micrographs ( $n=6$ for each mouse genotype per time point). Scale bar $=50 \mu \mathrm{m}$. ${ }^{*} P<0.05$. 
man scarring, it is difficult to distinguish between these two entities. ${ }^{7}$

\section{CXCR3 Signaling Affects Epidermal Regulation of Dermal Activity}

The altered pathology seen in hypertrophic scars is, at least in part, explained by the abnormalities in the cross talk between the two layers, the dermis and epidermis. ${ }^{28}$ We have previously shown that the CXCR3 signaling system is a mediator of keratinocyte to fibroblast signaling, and thus may play a role in synchronizing wound resolution. ${ }^{4}$ IP-9 is a key ligand of CXCR3 that stimulates differentiated basal keratinocytes to limit fibroblast migration in the dermis while simultaneously promoting reepithelialization of the epidermis. ${ }^{4,18}$ As such, we speculated that it is the lack of this CXCR3 signaling system that presents the CXCR3-devoid mice with scars that resemble a hypertrophic scar. To test whether IP-9 may act as a soluble paracrine factor, we isolated fibroblasts from both $\mathrm{CXCR}^{-1-}$ and wild-type mice for use in a Transwell co-culture wound assay. ${ }^{4}$ Keratinocytes were seeded in top inserts and stimulated with IFN- $\gamma$ to produce IP-9, and fibroblasts were seeded at the bottom wells and assessed in an in vitro wound healing assay. Both primary dermal fibroblasts (wild-type and $\mathrm{CXCR}^{-1-}$ ) migrated in response to EGF stimulation, but wild-type fibroblast motility was limited by IFN- $\gamma$ stimulated keratinocytes production of IP-9 (Figure 5); abrogation of IP-9 with a neutralizing antibody prevented this paracrine inhibition of motility. As expected, $\mathrm{CXCR}^{-1-}$ fibroblast motility was unaffected by the paracrine signaling (Figure $5 A$ ). As a control, similar results were found by directly exposing the stimulated fibroblasts to recombinant IP-9/ CXCL11 (Figure 5B). The CXCR3 ${ }^{-1-}$ fibroblast failed to limit their EGF-induced closure in the presence of IP-9 production. These data suggest that CXCR3 signaling system acts in a paracrine fashion to modulate epidermal-dermal maturation, and its absence results in the development of hypertrophic scars.

\section{Wound in the Absence of CXCR3 Present a Persistent Inflammatory Milieu}

Failure to heal wounds is associated with persistence of the inflammatory phase; although there are questions as to which comes first, it is well-accepted that the presence of inflammatory cells is not compatible with wound maturation $^{20}$ and leads to scarring. ${ }^{29}$ CXCR3 ligands both attract and activate cells that comprise both acute and chronic inflammation. ${ }^{12,30-32}$ Thus, it was contrary to expectation that no decrement was noted in the inflammatory response during the initial months of wound repair in the $\mathrm{CXCR}^{-1-}$ mice, ${ }^{18}$ thus arguing for significant redundancy in this process. Histopathology analyses of the wounds at 180 days presented a reappearance of the inflammatory response in the $\mathrm{CXCR}^{-1-}$ mice (Figure 6A). Unexpectedly, polymorphonuclear leukocytes and macrophages/monocytes were seen in the wounds of
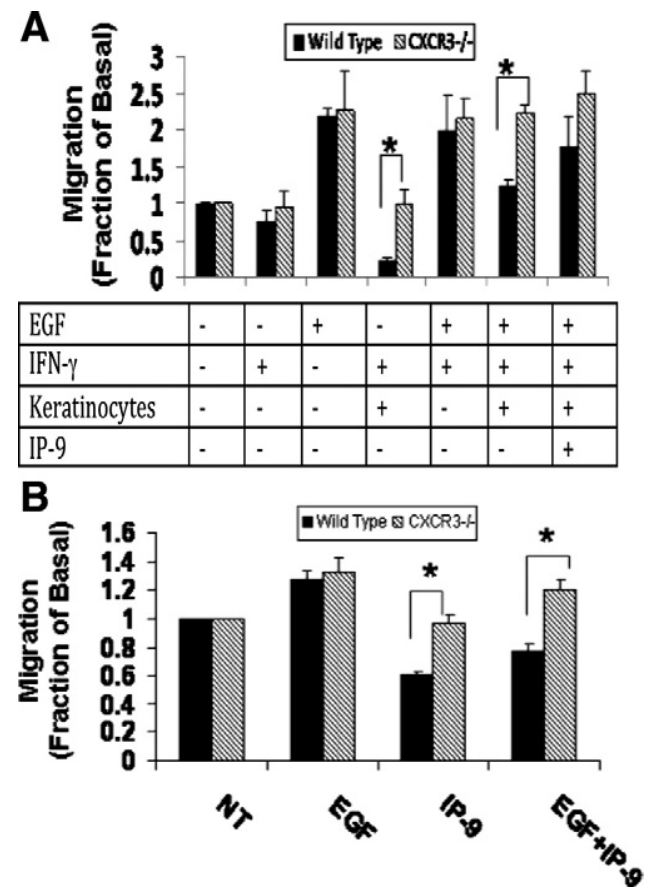

Figure 5. CXCR3 regulates dermal-epidermal cross talk. A: Keratinocytefibroblast co-cultures were established in a Transwell system. ${ }^{4}$ Inserts with or without keratinocytes were treated with or without IFN- $\gamma$ and/or EGF for 24 hours, and the fibroblast in the bottom wells were tested for motility by using a wound healing assay. Fibroblast cell motility was measured and showed that the motility of fibroblasts derived from $\mathrm{CXCR}^{-/-}$mice was not limited by the stimulation of keratinocytes by IFN- $\gamma$, unlike that of the wild-type fibroblasts. The addition of anti-CXCL11 antibody blocked the inhibitory effects of IP-9 on the wild-type mice fibroblast, whereas CXCR3 ${ }^{-/-}$fibroblast motility was unchanged. B: Fibroblasts alone were stimulated with recombinant CXCL11 with or without EGF, and tested for motility. EGF-induced motility of fibroblasts from the wild-type mice was blocked by the addition of CXC11, unlike that of CXCR3 ${ }^{-1-}$ fibroblast motility. Shown is the mean \pm SEM of $n=3$, each in triplicate; ${ }^{*} P<0.05$.

$\mathrm{CXCR}^{-1-}$ mice (Figure 6B). This inflammatory response was not because of bacterial infection because tissue Gram staining failed to detect microbes (Figure 6C) in both the wild-type and $\mathrm{CXCR}^{-1-}$ mice, and the overlying epidermis was intact. These data suggest that the inflammatory response may play a pivotal role in excessive scarring.

Inflammation is linked to angiogenesis, ${ }^{12}$ thus we examined the vascularity of these scars. Because CXCR3 signaling is not only angiostatic ${ }^{14}$ but also drives, at least in part, the wound resolution-phase vascular involution, ${ }^{9,33}$ we expected the increased vascularity noted in the absence of CXCR3 (Figure 6D). Quantification of $\mathrm{CXCR}^{-1-}$ wounds over time reveals a constant presence of vascularity (Figure 6D).

\section{Lack of IP-9 Production Results in Excessive Scarring}

The above results demonstrate a central role for $\mathrm{CXCR} 3$ signaling in the resolution of wound healing. However, because CXCR3 is ubiquitous on formed elements, the issue as to its specificity in wounds remains to be confirmed. We used a mouse in which expression of the CXCR3 ligand, IP-9/CXCL11, is abrogated in keratino- 
A

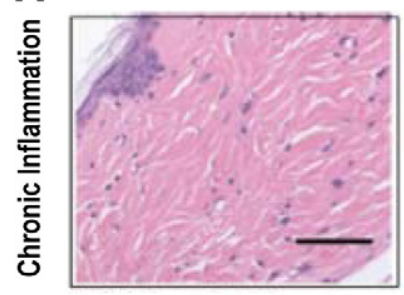

Wild Type D180
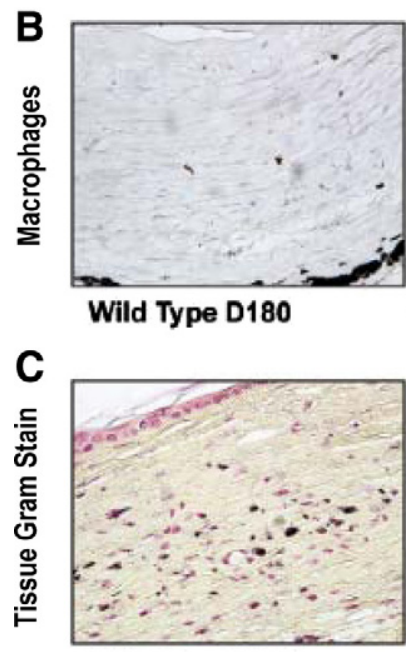

Wild Type D180

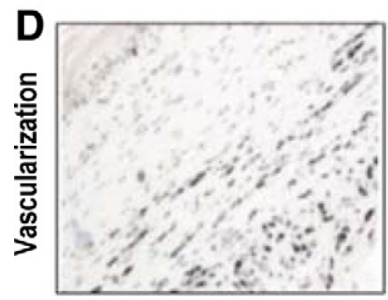

Wild Type D180

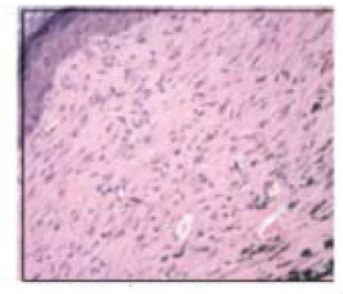

CXCR3-/-D180

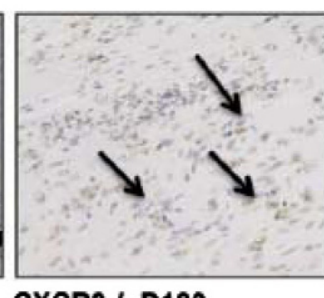

CXCR3\%-D180

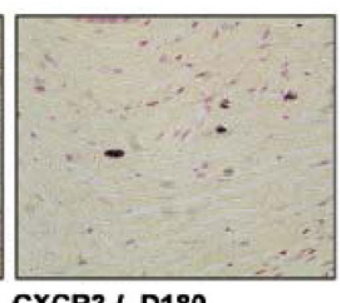

CXCR3 $/-D 180$

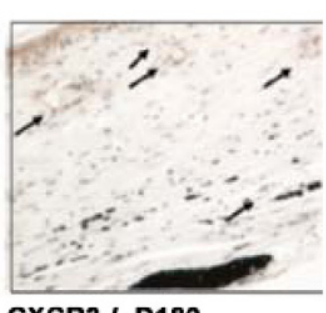

CXCR3-/-D180

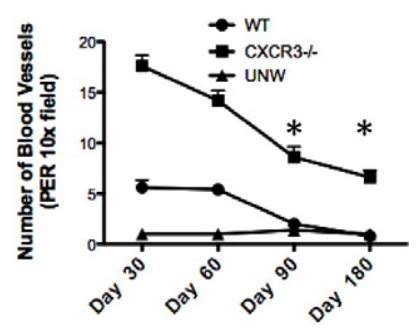

Figure 6. Recrudescence of an inflammatoryangiogenic response in persistent wound beds. A: Histopathological analysis of the acute and chronic inflammatory responses determined that there was a difference in macrophage or mononuclear leukocyte infiltration in the wounds of $\mathrm{CXCR}^{-/-}$mice compared with wild-type mice. B: $\mathrm{CXCR}^{-/-}$mice wound biopsies stained and quantified for increased macrophages in comparison with wild-type (WT) mice are shown.

(Arrows indicate macrophages stained cells). C: Gram stain revealed no bacterial infection in both $\mathrm{CXCR}^{-1-}$ and wild-type mice. D: Excessive numbers of blood vessels persisted in the wounds of mice lacking CXCR3. Neovascularization in $\mathrm{CXCR}^{-\prime-}$ mice was assessed by using immunostaining of von Willebrand factor antigen outlining blood vessels of the mice. Representative von Willebrand factor immunostaining demonstrates the paucity of capillaries at day 180 in wild-type wounds compared with the $\mathrm{CXCR}^{-1-}$ wounds. Quantitative analyses of vascularization of $\mathrm{CXCR}^{-/-}$mice wounds over time are shown in the graph. Representative micrographs are shown ( $n=6$ for each mouse genotype per time point). Scale bar $=50 \mu \mathrm{m}$ ${ }^{*} P<0.05$. cytes (IP-9AS), ${ }^{18}$ the main source of this ligand late in the wound repair process. ${ }^{10}$ Representative H\&E-stained sections of wounds in these mice showed both immaturity of the upper dermis and a thick hypercellular and hyperkeratinized epidermis at both 180 and 360 days after wounding (Figure 7A). The dermis of wounds in the IP9AS mice exhibited an increase in the number of cell layers that constitute the cellular epidermis in comparison with the control FVB mice (Figure 7B). These results correlate with the deficiencies in epidermal maturation showing that IP-9 production is a key aspect of keratinocytes progression in a wound (Figure 7C).

Because both fibroplasia and epithelialization are two distant aspects of skin healing, it is surprising that deficient epidermal maturation caused by the lack of IP-9 productions would lead to deficiencies in dermal maturation. Even though Masson's Trichrome staining for collagen content shows no significant difference between the IP-9AS mice and FVB (Figure 7D), there was a clear difference in maturity and alignment of collagen fibers. IP-9AS mice wounds had shorter and less wellconnected collagen fibers in direct contrast to the long, thick, and organized fibers seen in the FVB mice (Figure 7E). These data suggest that organization of the matrix is indirectly linked to the maturation of the epidermal layer and is likely modulated by the production of IP-9 via keratinocytes.

\section{Discussion}

Excessive scarring is a dermal fibrotic condition that results in inelastic, thick, and itchy scars that present serious functional and health problems for patients. ${ }^{1}$ At the onset of injury, keratinocytes proliferate and migrate over the wound defect to repave the denuded area. During this process, the migrating keratinocytes release factors, which has been suggested to control the recovery and maturation of the underlying dermis, including directing the expression, secretion, and functioning of components produced by dermal cells (fibroblasts). ${ }^{28}$ With minimal direct cell-cell contact, the keratinocytefibroblast communication mainly is thought to be regulated by releasable soluble factors acting in an autocrine/ 


\section{A}
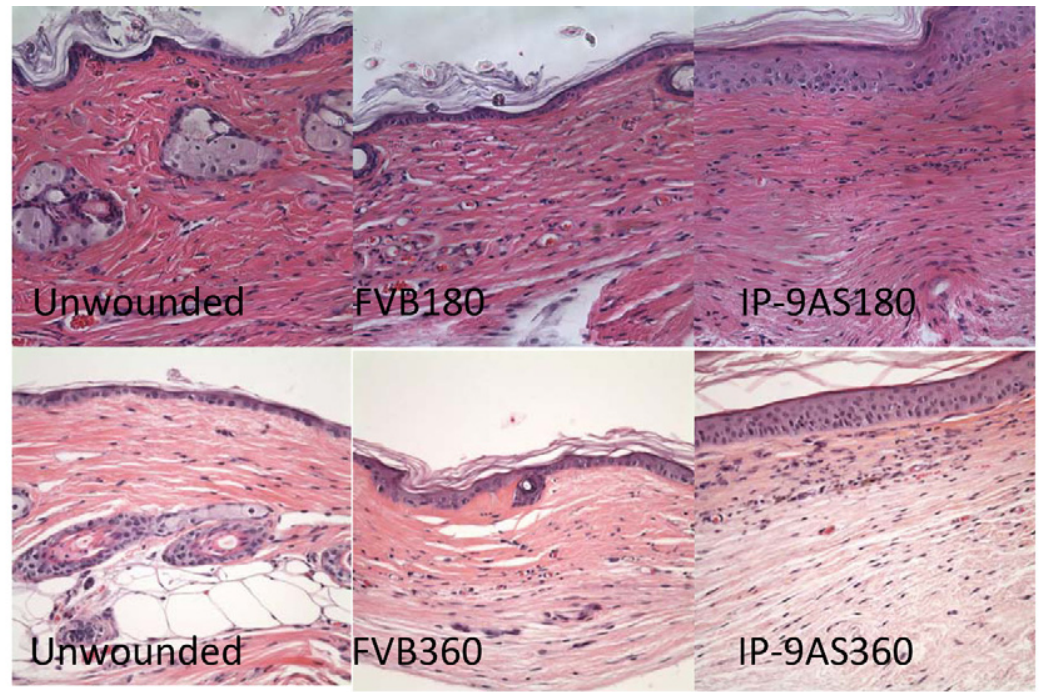

B
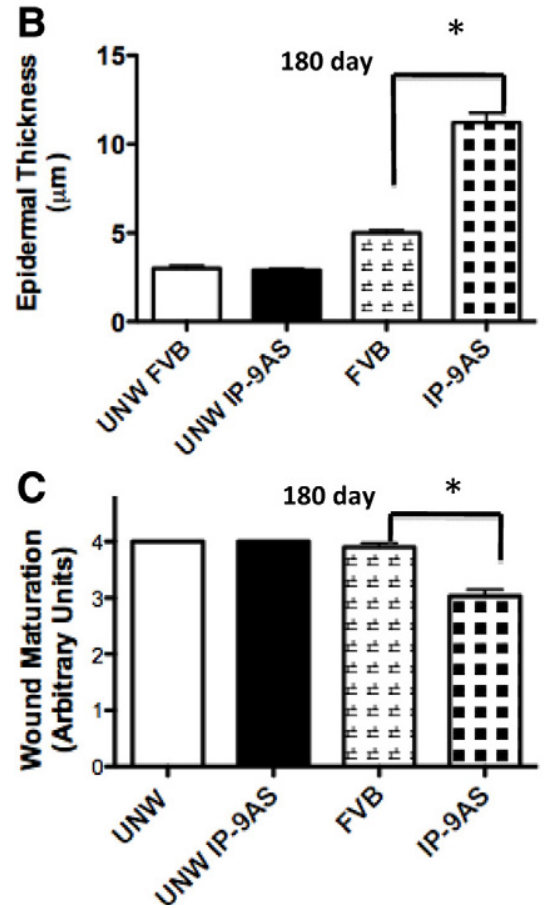

D
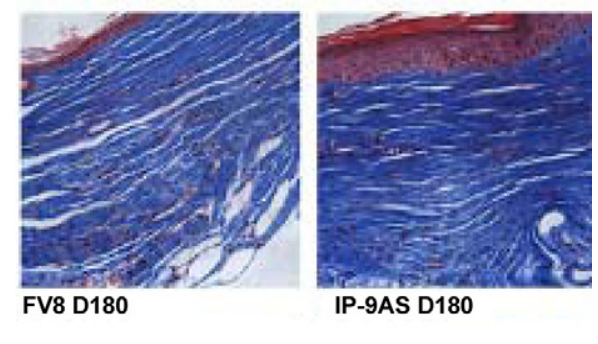

E

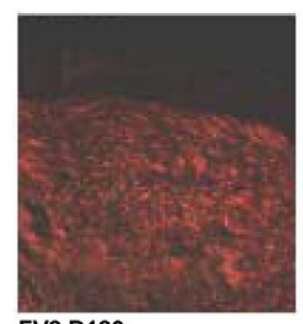

FV8 D180

paracrine loop. These soluble factors have been proposed as the communicators that synchronize the wound response, particularly during maturation phase during which they synchronize the termination of wound repair. It has been hypothesized that hypertrophic scarring results from the fibroplasia and its overproduction of extracellular matrix (along with immaturity of the matrix) secondary to abnormalities in epidermal-dermal cross talk. All this suggests a defect in the healing termination signaling. We have recently found that signaling through the CXCR3 receptor plays a major role in wound maturation; in the absence of this signaling system, there results an immature and hypercellular skin during the initial months after wounding. ${ }^{8,9,18}$ Still, these wounds closed similarly to wounds in wild-type mice, yet the full resolution appeared to be significantly retarded. Still, because wound repair has many redundancies, the question
Figure 7. Long-term ablation of IP-9 production results in deficient wound maturation. Epidermal maturation, determined by histopathological examination, showed excessive and dysfunctional scars 180 days after wounding of IP-9AS mice. A: Representative H\&E-stained sections revealed the dermal phenotype of these wounds converge toward but do not reach the state noted in wounds in CXCR3 mice (Figure 1); still these are evidently abnormal compared with unwounded skin, 180-day and 360-day wounds in FVB mice. B: Quantitative measurements of epidermal cell layers show IP-9AS mice full-thickness wounds to be significantly thicker 180 days after wounding in comparison with FVB mice. C: Wound maturation of 2-cm full-thickness wounds of IP-9AS mice was deficient in comparison with FVB mice. D: Masson's Trichrome (upper) and (E) Picrosirius Red (lower) staining showed similar amounts of collagen but shorter, less organized collagen fibers between the IP-9AS and FVB mice 180 days after wounding. Shown are representative photomicrographs of entire wound in $\mathbf{A}, \mathbf{D}$ and $\mathbf{E}$ of six mice. Scale bar $=50 \mu \mathrm{m}$. Original magnification, $\times 400$. In $\mathbf{B}$ and $\mathbf{C}$, the mean $\pm \mathrm{SD}$ are shown $\left(n=6,{ }^{*} P<0.05\right.$; where no error bars are noted, they are subsumed within the bar). arose as to whether this could lead to a hypertrophic scarring situation. Thus, we undertook an examination of longer term wounds to determine whether this represents merely a retardation in wound resolution or an actual persistent pathology such as noted in human conditions.

Extending the wound analyses to 180 days showed not just a retardation of, or even a persistence of, but a reversion to greater immaturity in the wounds in $\mathrm{CXCR}^{-1-}$ mice. This is a critical distinction in that at 180 days the phenotype became more pronounced beyond that which was noted at only 90 days; for instance, the hyperkeratinization was now overtly noticeable, the deficit in tensile strength widened, and the inflammatory infiltrate reappeared. The immaturity of the matrix constituency has implications beyond lessened strength. Fibronectin and tenascin $\mathrm{C}$ present a different set of integrin ligands than collagen, altering the adhesiveness 
profiles, with implications for the proliferation and migration of the cellular elements. ${ }^{34}$ Further, tenascin C presents cryptic ligands (matrikines) that activate EGF receptors to promote fibroblast and endothelial cell immigration and maintain fibroblasts in a "dedifferentiated," noncontractile state. ${ }^{35,36}$ Thus, this matrix immaturity, in part promoted by leukocyte-derived proteases, contributes to a feed-forward loop in which the wound bed not only fails to heal but remains in an active, immature state contributing to the further scarring. Whether this will result in keloids or hypertrophic scarring is unknown at this time. Because the early stages (up to 1 year) of both types of wound misadventures may appear similar, one cannot prejudge. Leaning toward hypertrophic scarring is the involvement of the hypercellular epidermis (in true keloids the epidermis appears to contain near normal keratinocyte complement and stratification), though the highly active ongoing matrix turnover and multilineage cellularity does suggest ultimate keloid generation. The hypertrophic scarring in this mouse model is histologically similar to that found in a scar model caused by wound tension in which both the dermal and epidermal compartments are hypercellular. ${ }^{2}$ The similarity of these scars leaves open whether in rodent skin dermal and epidermal hypertrophy are more linked or whether this is the common initial stage of both forms of scarring. However, the short life-span of the mouse, coupled with reduced responsiveness to mitogenic ligands of dermal fibroblasts, ${ }^{37,38}$ confounds easy answers to this in mouse models.

There are multiple genetically distinct ligands specific for CXCR3-CXCL4 (PF4), CXCL9 (MIG), CXCL10 (IP-10), and CXCL11 (IP-9 or I-TAC). Although we have some evidence based on experimentation and literature reports of time of expression that IP-10 and IP-9 predominate in synchronizing the wound maturation, ${ }^{10,11,18}$ it is possible that there is an unappreciated redundancy in these ligands. Thus, we used a model in which the common CXCR3 receptor is negated. Although this may appear to be too extensive to examine just wound healing, because CXCR3 is ubiquitously expressed on all cells including stem, hematopoietic, and inflammatory cells, ${ }^{12,39}$ the lack of this receptor impacts the entire systemic response to even localized wounds (ie, inflammatory response and recruitment of cells). That these mice develop apparently normally demonstrates key redundancies for these processes, allowing us to profitably pursue wound response studies in these animals. ${ }^{8,9,18}$ We have chosen not to attempt deletion of CXCR3 acutely because the need for near complete abrogation would be technically challenging over the time course of 6 months for the scar to develop. Furthermore, cell-specific knockouts were also not attempted because the numerous cell types involved required a large number of individual arrogations and combinations of such. There is also the issue of circulating precursors for fibroblasts ${ }^{40}$ and endothelial cells ${ }^{41}$ that would confound targeted deletions. Studies in which a specific ligand (IP-9/CXCL11/I-TAC) was abrogated in a single cell type (keratinocytes) confirmed the fidelity of the global CXCR3 knockout. ${ }^{18}$ In this study, the hypertrophic scar phenotype that we achieved by examining long-term wounds in mice in which the keratinocyte-produced IP-9 was abrogated by K5 promoter induction of an antisense construct. The epidermal thickening and hyperkeratinization were similar to the wounds in the CXCR-devoid mice, though the dermal immaturity was less pronounced. This dichotomy of fidelity is expected because of the role of IP-9 in dermal-epidermal communication ${ }^{4}$ with CXCR3 being activated in the deeper dermis mainly by IP-10. ${ }^{10}$ The convergence of phenotype in these two mice validates the centrality of the CXCR3 signaling axis wound resolution.

Lastly, there is concern about the CXCR3 isoform. Hematopoietic cells express predominantly the A isoform, whereas the formed elements (fibroblasts, endothelial cells, and keratinocytes) express almost exclusively the $B$ isoform. Because the $B$ isoform is generated by $5^{\prime}$ alternative splicing, negation of a singular isoform may in fact drive the cells to produce the other isoform and thus fail to negate the system. In dysregulated epithelial cells, carcinoma cells, initial studies and literature reports find both isoforms expressed on the same cell. ${ }^{42}$ The isoform specification appears to be most important for designating differential ligand sensitivity, whereas signaling is achieved via usage of different heterotrimeric G proteins. ${ }^{14,15}$ Thus, we feel justified in deleting both isoforms.

It was curious to detect a recrudescence of an inflammatory response involving cells of the acute response. Over the initial month period, the inflammatory response was similar in wounds made in the wild-type, $\mathrm{CXCR}^{-1-}$, and IP-9-negated mice. ${ }^{9,18}$ However, at 6 months, the wounds in $\mathrm{CXCR}^{-1-}$ mice showed an inflammatory infiltrate. Although one may be tempted to conclude that the inflammation flowed from the failure to resolve the healing response, it is possible that delayed re-epithelialization and basement membrane dysfunction ${ }^{8}$ allows infection and subsequent inflammation, though the synchrony of the six mice involved argue against this. Perusal of the biopsy did not reveal active bacterial/fungal infection or colonization of the dermis, hinting at a sterile inflammatory infiltration. Still, whether this inflammatory response is primary or secondary, it would serve to further accentuate an actively turning over, immature wound bed.

It should be noted that although most of the formed elements of the healed skin derive from adjacent, unwounded tissues, there might be contribution of cells that derive from distal sites, the bone marrow primary among these. ${ }^{40}$ This is especially true of endothelial cells and their circulating precursors. ${ }^{41,43}$ Because these cells differentiate into the same lineages, and seemingly indistinguishably, as the adjacent resident cells, there is no reason to suspect that such cells would be affected differently as the adjacent cells. One could envision that in the absence of CXCR3 signaling, such precursor cells would have greater seeding because the negative migratory signals are absent. However, further experimentation, lying beyond the scope of the present communication, would be required to resolve this issue.

In conclusion, we have found a situation in which a wound bed continues to undergo the regenerative process and even experiences an inflammatory recrudescence over an extended time period leading to a hyper- 
trophic and hypercellular but weakened scar situation. This is not merely severe retardation of resolution because we note increased re-expression of immature matrix components and even an inflammatory response that had resolved by 30 days. ${ }^{9,18}$ In many ways, the properties and histology of these wounds are reminiscent of human hypertrophic scars, yet they do not fully recapitulate either the hypertrophic scar or the keloid situation. ${ }^{7}$ The epidermal hypercellularity and the renewed inflammatory processes do distinguish these scars, and those formed from wound tension, ${ }^{2}$ from the human pathologies. Still, these findings not only highlight a central role for CXCR3 signaling in wound resolution but also define a novel animal model for persistent healing and hypertrophic scarring.

\section{Acknowledgments}

We thank Diane George for technical assistance and Drs. Patricia Hebda, Anand lyer, and Shao Hanshuang for suggestions and discussions.

\section{References}

1. Singer AJ, Clark RAF: Cutaneous wound healing. N Engl J Med 1999, 341:738-746

2. Aarabi S, Bhatt KA, Shi Y, Paterno J, Change El, Loh SA, Holmes JW, Longaker MT, Yee H, Gurtner GC: Mechanical load initiates hypertrophic scar formation through decreased cellular apoptosis. FASEB J 2007, 21:3250-3261

3. Machesney M, Tidman N, Waseem A, Kirby L, Leigh I: Activated keratinocytes in the epidermis of hypertrophic scars. Am J Pathol 1998, 152:1133-1141

4. Satish L, Yager D, Wells A: ELR-negative CXC chemokine IP-9 as a mediator of epidermal-dermal communication during wound repair. J Invest Dermatol 2003, 120:1110-1117

5. Ramos ML, Gragnani A, Ferreira LM: Is there an ideal animal model to study hypertrophic scarring. J Burn Care Res 2008, 29:363-368

6. Zhu KQ, Carrougher GJ, Gibran NS, Isik FF, Engrav LH: Review of the female Duroc/Yorkshire pig model of human fibroproliferative scarring. Wound Repair Regen 2007, 15:S32-S39

7. Ehrlich HP, Desmouliere A, Diegelmann RF, Cohen IK, Compton CC Garner WL, Kapanci Y, Gabbiani G: Morphological and immunochemical differences between keloids and hypertrophic scar. Am J Pathol 1994, 145:105-113

8. Yates CC, Whaley D, Hooda S, Hebda PA, Bodnar RJ, Wells A: Delayed re-epithelialization and basement membrane regeneration after wounding in mice lacking CXCR3. Wound Repair Regen 2009, 17:34-41

9. Yates CC, Whaley D, Kulasekeran P, Hancock WW, Lu B, Bodnar R, Newsome J, Hebda PA, Wells A: Delayed and deficient dermal maturation in mice lacking the CXCR3 ELR-negative CXC chemokine receptor. Am J Pathol 2007, 171:484-495

10. Tensen CP, Flier J, vanderRaaij-Helmer EM, Sampat-Sardjoepersad S, vanderSchors RC, Leurs R, Scheper RJ, Boorsma DM, Willemze R: Human IP-9: a keratinocyte-derived high affinity CXC-chemokine ligand for the IP-10/Mig receptor (CXCR3). J Invest Dermatol 1999, 112:716-722

11. Luster AD, Greenberg SM, Leder P: The IP-10 chemokine binds to a specific cell surface heparan sulfate site shared with platelet factor 4 and inhibits endothelial cell proliferation. J Exp Med 1995, 182:219-231

12. Romagnani $P$, Lasagni L, Annunziato F, Serio M, Romagnani S: CXC chemokines: the regulatory link between inflammation and angiogenesis. Trends Immunol 2004, 25:201-209

13. Shiraha H, Glading A, Chou J, Jia Z, Wells A: Activation of m-calpain (calpain II) by epidermal growth factor is limited by PKA phosphorylation of m-calpain. Mol Cell Biol 2002, 22:2716-2727
14. Bodnar R, Yates C, Wells A: IP-10 blocks VEGF-induced endothelial cell motility and tube formation via inhibition of calpain. Circ Res 2006, 98:617-625

15. Satish L, Blair HC, Glading A, Wells A: IP-9 (CXCL11) induced cell motility in keratinocytes requires calcium flux-dependent activation of $\mu$-calpain. Mol Cell Biol 2005, 25:1922-1941

16. Hancock WW, Lu B, Gao W, Csizmadia V, Faia K, King JA, Smiley ST, Ling M, Gerard NP, Gerard C: Requirement of the chemokine receptor CXCR3 for acute allograft rejection. J Exp Med 2000, 192:1515-1520

17. Murillas R, Larcher F, Santos M, Ullrich A, Jorcano JL: Expression of a dominant negative mutant of epidermal growth factor receptor in the epidermis of transgenic mice elicits striking alterations in hair development and skin structure. EMBO J 1995, 14:5216-5223

18. Yates CC, Whaley D, Yen A, Kulesekaran P, Hebda PA, Wells A: ELR-negative CXC chemokine CXCL11(IP-9/I-TAC) facilitates dermal and epidermal maturation during wound repair. Am J Pathol 2008, 173:643-652

19. Lee JY-Y, Yang C-C, Chao S-C, Wong T-W: Histopathological differential diagnosis of keloid and hypertrophic scar. Am J Dermatopathol 2004, 26:379-384

20. Clark RAF (Ed): The Molecular Cell Biology of Wound Repair. New York, Plenum Press, 1996, pp 31-36

21. Shao $H$, Yin $X-M$, Wells $A$ : Epidermal growth factor protects fibroblasts from apoptosis via $\mathrm{Pl} 3$ kinase and rac signaling pathways. Wound Repair Regen 2008, 16:551-558

22. Allen FD, Asnes CF, Chang P, Elson EL, Lauffenburger DA, Wells A: EGF-induced matrix contraction is modulated by calpain. Wound Repair Regen 2002, 10:67-76

23. Akasaka Y, Fujita K, Ishikawa $Y$, Asuwa N, Inuzuka K, Ishihara M, Ito M, Masuda T, Akishima Y, Zhang L, Ito K, Ishii T: Detection of apoptosis in keloids and a comparative study on apoptosis between keloids, hypertrophic scars, normal healed flat scars, and dermatofibroma. Wound Repair Regen 2001, 9:501-506

24. Chuong CM, Chen HM: Enhanced expression of neural cell adhesion molecules and tenascin (cytotactin) during wound healing. Am J Pathol 1991, 138:427-440

25. Sible JC, Rettig WJ, Eriksson E, Smith SP, Oliver N: Gene expression of tenascin is altered in normal scars and keloids. Wound Repair Regen 1995, 3:37-48

26. Lim IJ, Phan TT, Bay BH, Qi R, Huynh H, Tan WT, Lee ST, Longaker MT: Fibroblasts cocultured with keloid keratinocytes: normal fibroblasts secrete collagen in a keloid-like manner. Am J Physiol Cell Physiol 2002, 283:C212-C222

27. Ala-Kokko L, Rintala A, Savolainen ER: Collagen gene expression in keloids: analysis of collagen metabolism and type I, III, IV, and V procollagen mRNAs in keloid tissue and keloid fibroblast cultures. J Invest Dermatol 1987, 89:238-244

28. Babu M, Wells A: Dermal-epidermal communication in wound healing. Wounds 2001, 13:183-189

29. Singer AJ, McClain SA: Persistent wound infection delays epiderma maturation and increases scarring in thermal burns. Wound Repair Regen 2002, 10:372-377

30. Jinquan T, Jing C, Jacobi HH, Reimert CM, Millner A, Quan S, Hansen JB, Dissing S, Malling HJ, Skov PS, Poulsen LK: CXCR3 expression and activation of eosinophils: role of IFN-gamma-inducible protein-10 and monokine induced by IFN-gamma. J Immunol 2000, 165:1548-1556

31. Farber JM: Mig and IP-10: CXC chemokines that target lymphocytes. J Leukoc Biol 1997, 61:246-257

32. Loetscher M, Gerber B, Loetscher P, Jones SA, Piali L, Clark-Lewis I, Baggiolini M, Moser B: Chemokine receptor specific for IP10 and MIG: structure, function, and expression in activated T-lymphocytes. $J$ Exp Med 1996, 184:963-969

33. Bodnar RJ, Yates CC, Du X, Wells A: ELR-negative chemokine IP-10/ CXCL10 induces dissociation of newly-formed vessels secondary to calpain cleavage of beta3 integrin. J Cell Sci 2009, 122:2064-2077

34. Juhasz I, Murphy GF, Yan HC, Herlyn M, Albelda SM: Regulation of extracellular matrix proteins and integrin cell substratum adhesion receptors on epithelium during cutaneous human wound healing in vivo. Am J Pathol 1993, 143:1458-1469

35. Tran KT, Griffith LG, Wells A: Extracellular matrix signaling through growth factor receptors during wound healing. Wound Repair Regen 2004, 12:262-268 
36. Iyer AKV, Tran KT, Griffith L, Wells A: Cell surface restriction of EGFR by a Tenascin cytotactin-encoded EGF-like repeat is preferential for motility-related signaling. J Cell Physiol 2007, 214:504-512

37. Tang Z, Zhang Z, Zheng Y, Corbley MJ, Tong T: Cell aging of human diploid fibroblasts is associated with changes in responsiveness to epidermal growth factor and changes in HER-2 expression. Mech Ageing Dev 1994, 73:57-67

38. Shiraha H, Gupta K, Drabik KA, Wells A: Aging fibroblasts present reduced epidermal growth factor (EGF) responsiveness due to preferential loss of EGF receptors. J Biol Chem 2000, 275:19343-19351

39. Chamberlain G, Fox J, Ashton B, Middleton J: Mesenchymal stem cells: their phenotype, differentiation capacity, immunological feature, and potential for homing. Stem Cells 2007, 25:2739-2749
40. Opalenik SR, Davidson JM: Fibroblast differentiation of bone marrowderived cells during wound repair. FASEB J 2005, 19:1561-1563

41. Garmy-Susini B, Varner JA: Circulating endothelial progrenitor cells. Br J Cancer 2005, 93:855-858

42. Datta D, Contreras AG, Grimm M, Waage-Gasser AM, Briscoe DM, Pal S: Calcineurin inhibitors mediate CXCR3 splice variant expression and mediate renal cancer progression. J Am Soc Nephrol 2008, 19:2437-2446

43. Gallagher KA, Liu ZJ, Xiao M, Chen H, Goldstein LJ, Buerk DG, Nedeau A, Thom SR, Velazquez OC: Diabetic impairments in NOmediated endothelial progenitor cell mobilization and homing are reversed by hyperoxia and SDF-1 alpha. J Clin Invest 2007, 117:1249-1259 